\title{
DETERMINATION OF OXYGEN PERFUSION IN THE AREA OF RADIATION-INDUCED FIBROSIS OF THE SKIN IN PATIENTS WITH BREAST CANCER AND ITS ROLE IN PATHOGENESIS OF LATE RADIATION INJURY
}

\author{
T.T. Agishev', E.E. Topuzov', D.A. Krasnozhon', A.O. Petrachkov, ${ }^{3}$ R.V. Pavlov ${ }^{3}$, S.H. Doniyarov ${ }^{4}$ \\ ${ }^{1}$ Saint Petersburg Regional Oncology Dispensary, Saint Petersburg 197022, Russia \\ 2I.I. Mechnikov North-Western State Medical University, Ministry of Health of Russia, \\ Saint-Petersburg 191015, Russia \\ ${ }^{3}$ N.N. Petrov Research Institute of Oncology, Ministry of Health of Russia, \\ Saint Petersburg 197758, Russia \\ ${ }^{4}$ Saint Petersburg State Pediatric Medical University, Saint Petersburg 194100, Russia
}

\begin{abstract}
Aim: Late radiation injury in the form of radiation-induced fibrosis (RIF) is one of the many complications of radiation therapy. The aim was to evaluate oxygen perfusion in the skin in the area of late radiation injury manifested as RIF in patients with breast cancer. Materials and Methods: Based on our first-hand experience in treating late radiation injures of soft tissues in patients with breast cancer, we measured oxygen perfusion of the skin $\left(\mathrm{tcpO}_{2}\right)$ in the area of late radiation injury using a transcutaneous monitor (oximeter) TCM 400 (Radiometer, Denmark). Results: Partial oxygen pressure tcp $\mathrm{O}_{2}$ in the RIF area in patients with breast cancer didn't show any significant decrease compared to healthy tissue. Mean value of partial oxygen pressure tcp $\mathrm{O}_{2}$ in the $\mathrm{RIF}$ area was $42.650 \pm 9.178 \mathrm{mmHg}$, in the healthy tissue it was $45.180 \pm 8.025 \mathrm{mmHg}$. Maximal difference in tcp $\mathrm{O}_{2}$ between the damaged and healthy tissue was $30 \mathrm{mmHg}$. Conclusions: Results of the study suggest that there's no significant difference between oxygen perfusion $\left(\operatorname{tcp} \mathrm{O}_{2}\right)$ in the area of $\mathrm{RIF}$ and healthy tissue.
\end{abstract}

Key Words: breast cancer, late radiation injury, radiation-induced fibrosis of the skin, oxygen perfusion of the skin.

Radiation therapy remains one of the most effective and useful methods of treatment of malignant tumors, breast cancer in particular [1, 2]. Current understanding of ionizing radiation dose tolerance for various organs and tissues, improvement of regimen durations, as well as advancement of radiation sources, allow to achieve significant antitumor effect. However, during radiation therapy, not only tumor cells are damaged, but also healthy tissue, and there's a risk of radiation injury (RI) in the irradiated area leading to consistent changes in organs and tissues. These changes can significantly decrease patients' quality of life even after recovery. One of the many complications of radiation therapy is late $\mathrm{RI}$ manifesting as radiation-induced fibrosis (RIF) $[1,3,4]$.

RI can be early if it develops in the first three months after irradiation and late if it manifests later.

In literature, RIF pathogenesis is considered from several points of view. According to one of the hypotheses, the main cause of RIF pathogenesis is RI of the vessels due to ionizing radiation, especially capillary endothelium. At first, RI manifests as functional pathology of microcirculation and hypoxia in the irradiated tissue, and later it leads to morphological changes in the cells and formation of late manifestations

Submitted: October 04, 2017.

${ }^{\star}$ Correspondence: E-mail: tagishev@gmail.com

Abbreviations used: RI - radiation injury; RIF - radiation-induced fibrosis; tc $\mathrm{O}_{2}$ - transcutaneous oxygen pressure; TO - transcutaneous oximeter. of irradiation in the form of fibrosis and sclerosis which directly cause increasing hypoxia in the damaged area creating a positive feedback loop [1,5-8].

Another hypothesis considers one or several parenchyma cell populations in the tissue as the leading factor of RIF pathogenesis. In normal conditions, cellular regenerating system creates a state of stable balance between cell populations, and in case of death or migration of a cell population, it produces new elements restoring cell number. During exposure to ionizing radiation, the character of radiation reactions reflects proliferative ability of the target cells. Organs and tissues containing vegetative and differentiating cells respond to irradiation with acute reactions. In other cell types, the changes are less pronounced or absent altogether. Therefore, RI developing during irradiation or soon after is characteristic of rapidly regenerating tissues, and time to RI manifestation and its severity are determined by repopulation rate and cell radiosensitivity. For instance, irradiation of the skin (an example of rapidly regenerating tissue) leads to a decrease in the number of stem cells, or in other words, vegetative intermitotic cells. Then, the number of more differentiated cells - differentiating intermitotic and constant postmitotic cells - decreases. Later, breakage of the base membrane is observed, as well as altered local blood flow and changes in the vessel walls. If the total absorbed dose is lower than the "tolerable dose" for the irradiated tissue, then the pathological process gradually subsides, and the number of stem cells is restored during the next differentiation $[1,9,10]$. 
When the absorbed dose exceeds tolerance of the tissue to ionizing radiation, a number of radiationinduced changes occur leading to expansion of the connective tissue and formation of areas with intense cicatricial transformation. According to both hypotheses, expansion of the connective tissue is a time-delayed process, and this tissue serves as a substitute. However, structural and functional characteristics of the connective tissue change long before the development of histologically observed symptoms of fibrosis. The main trigger for development of local RI is damage to the fibroblasts, especially the immature, rapidly dividing populations that serve as the main structural element of the connective tissue. Current research is focused both on direct effect of radiotherapy on fibroblasts, and on the effects of the neighboring cells and factors during irradiation. Fibroblasts play a crucial role in wound healing by deposing and remodeling collagen fibers, and in the irradiated tissue the structure of these fibers becomes disorganized (due to possible dysregulation of matrix metalloproteases) $[1,11,12]$.

Questions related to determination of individual sensitivity to ionizing radiation and pathogenesis of local RI of the skin and subcutaneous fat, in particular after surgical treatment and radiation therapy in patients with breast cancer, remain open.

According to the "vessel hypothesis" of development of late RI, the leading factor of pathogenesis is local alteration of tissue microcirculation. Therefore, we decided to determine oxygen perfusion in the irradiated skin to confirm or rule out ischemia in this area.

Perfusion characterizes tissue respiration which, in turn, involves gas exchange, primarily of oxygen, in microcirculatory tissue systems, and redox reactions in mitochondria. The main physiological characteristics of these processes are oxygen delivery and oxygen consumption [15].

Transcutaneous oxygen $\left(\mathrm{tc} p \mathrm{O}_{2}\right)$ measurement is non-invasive monitoring of partial oxygen pressure in the skin. Unlike arterial pressure and blood flow rate, tcpO $\mathrm{O}_{2}$ is a direct measure of the state of microcirculation and reflects real oxygen delivery to skin cells. Changes in the partial oxygen pressure tc $p \mathrm{O}_{2}$ show changes in oxygen transport, its delivery and consumption and can help detect blood flow problems.

Principle of operation of a transcutaneous monitor. A set of sensors (Clark electrodes) placed on the skin measure blood gases entering the skin by diffusion. This method has gained widespread recognition due to its use in neonatology for evaluation of hypoxia in newborns and in treatment of trophic ulcers caused by diabetes mellitus. Moreover, transcutaneous oximeter (TO) can be used for controlling hyperbaric oxygenation and for optimization of implant survival.

Currently, non-invasive transcutaneous monitoring of tissue oxygen level tc $\mathrm{O}_{2}$ (oxygenation/microcirculation and skin perfusion) is a valuable and reliable diagnostic instrument [16].
The aim of the study was to evaluate oxygen perfusion in the skin in the area of late RI manifested as RIF in patients with breast cancer using TO TCM 400 (Radiometer, Denmark).

\section{MATERIALS AND METHODS}

Evaluation of transcutaneous local partial oxygen tissue saturation tc $\mathrm{O}_{2}$ using TO TCM 400 (Radiometer, Denmark) had been performed at the Regional Oncology Dispensary from September 2016 to May 2017. The study included 19 patients with breast cancer (stages I-III a), tc $\mathrm{O}_{2}$ was measured in the area of previous surgical treatment and irradiation and subsequent RI in the form of RIF. In the studied patients, time since the completion of radiotherapy to the measurement varied from 4 to 9 months. Patients' age was from 27 to 65 years. All of the patients were informed about the objective of the study before they were included and we have obtained the patients' informed consent. Sensors of partial oxygen tissue saturation tcp $\mathrm{O}_{2}$ were placed on the front axillary line in the area of RIF. The measurement was compared to partial oxygen tissue saturation tc $\mathrm{O}_{2}$ of an equivalent healthy non-irradiated tissue (a point on the frontal axillary line). During measurement point selection, a point above a homogenous capillary bed without large veins, skin defects, hair growth, or symptoms of significant tissue edema was chosen. To obtain significant comparable data, standard conditions were used: 1) environmental temperature was between 21 and $24^{\circ} \mathrm{C}$; 2 ) before the examination patients didn't smoke or ingest strong tea or coffee; 3 ) patients were stable (didn't perform physical exercises).

The main locations of late RI were the frontal rib cage (11 patients, $57.9 \%$ ) and mammary gland (8 patients, $42.1 \%)$. Severity of RI was evaluated using the LENTSOMA (Late Effects Normal Tissues - Subjective, Objective, Management and Analytic) scale. The scale provides a detailed description of clinical symptoms in organs and tissues in the irradiated area: grade $1-$ mild symptoms, no treatment need; grade 2 - symptoms more pronounced, require conservative treatment; grade 3 - severe symptoms significantly affecting quality of life, sometimes require surgical treatment; grade 4 - irreversible ulcerous and necrotic changes in soft tissues requiring surgical treatment [13].

In 7 patients with breast cancer, radiation-induced injury was grade $3(36.84 \%)$, in 10 patients grade $2(52.63 \%)$, and in 2 patients - grade $1(10.53 \%)$.

\section{RESULTS}

Partial oxygen pressure tc $p \mathrm{O}_{2}$ in the RIF area in patients with breast cancer didn't show a significant decrease compared to healthy tissue (Fig. 1). Mean value of partial oxygen pressure tc $\mathrm{O}_{2}$ in the RIF area was $42.650 \pm 9.178 \mathrm{mmHg}$, in the healthy tissue it was $45.180 \pm 8.025 \mathrm{mmHg}$. Normally, in healthy people partial oxygen pressure tc $p \mathrm{O}_{2}$ in the chest is $67 \pm 12 \mathrm{mmHg}$. Ischemia is diagnosed at values below $20 \mathrm{mmHg}$ [14]. Maximal difference in tc $\mathrm{O}_{2}$ between the damaged and healthy tissue was $30 \mathrm{mmHg}$. 


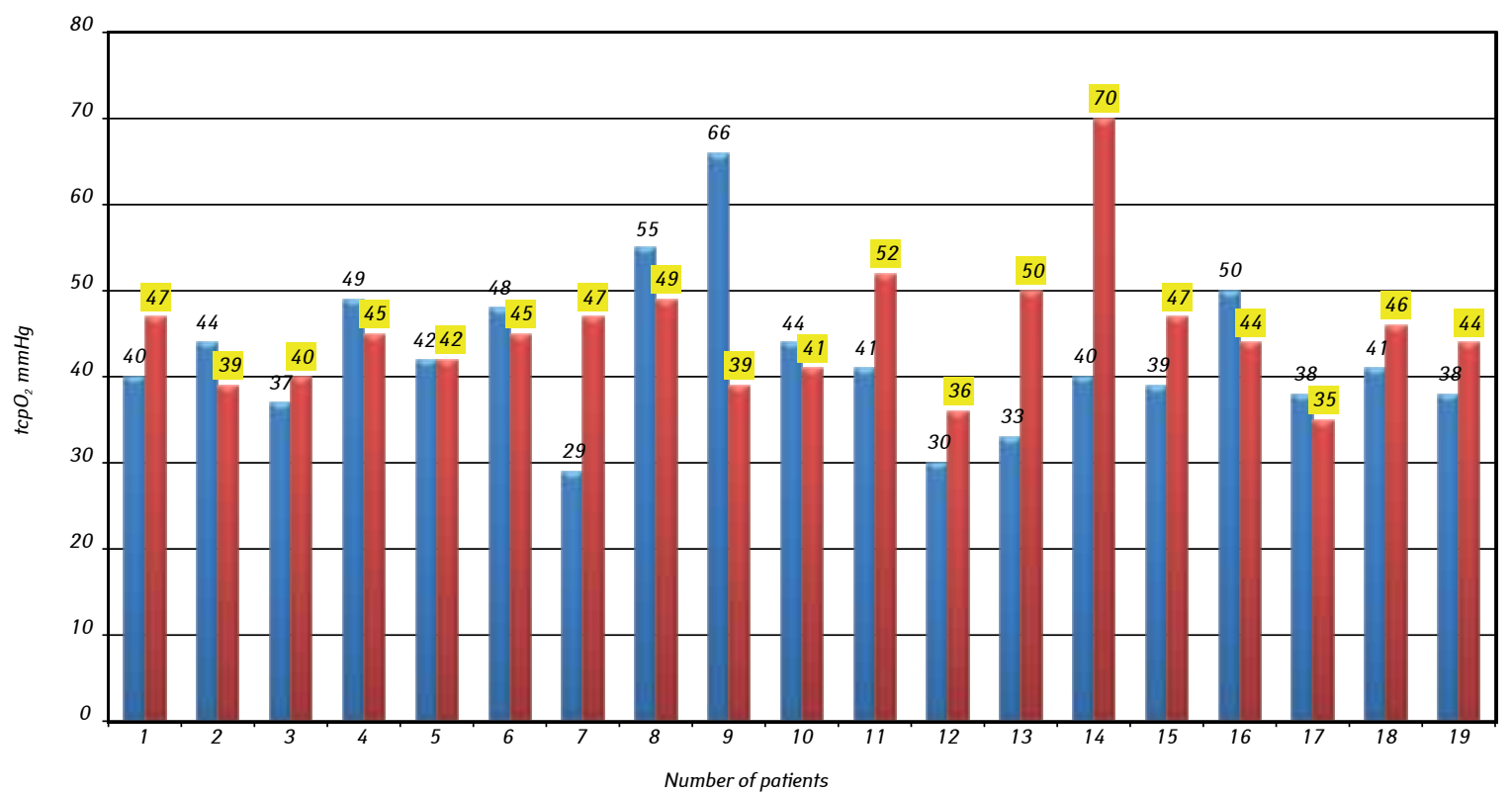

Fig. 1. Measurement of tcpO $\mathrm{O}_{2}$ in the skin in the area of late $\mathrm{Rl}$ compared to measurement in the healthy tissue. Red bars correspond to the healthy side, blue - to the RIF area

Comparison of transcutaneous partial pressure of oxygen didn't show statistically significant differences between the mean values in the affected and healthy sides (Fig. 2). Per the Wilcoxon signed-rank test, there are no significant differences $(p=0.338)$ between healthy tissue and tissue affected by RIF.
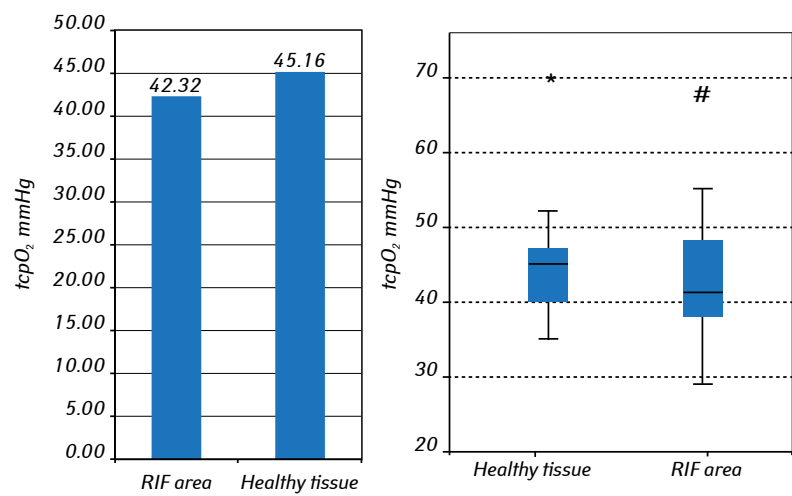

Fig. 2. Box plot of tcp $\mathrm{O}_{2}(\mathrm{mmHg})$ in tissues with late $\mathrm{RI}$ (RIF area) and healthy tissues $\left({ }^{*}\right.$ - outlier, ${ }^{*}$ - extremum)

\section{DISCUSSION AND CONCLUSIONS}

In accordance with several theories on pathogenesis, RI of the skin and subcutaneous fat causes:

- deficit of vegetative and differentiating intermitotic cells, fibroblasts in particular;

- disorganization of collagen fibers in the irradiated area;

- microcirculation disorder and hypoxia in the affected area.

Altered tissue microcirculation leads to decreased oxygenation and perfusion due to decreased oxygen delivery. According to the "vessel hypothesis" [18-20] of late RI pathogenesis, it is reasonable to assume a similar situation.

This assumption was the basis for evaluation of skin perfusion in the area of RIF and subsequent comparison of the data with equivalent healthy skin. For the study, we have chosen non-invasive monitoring of partial pressure of oxygen and, for the first time, evaluated oxygen perfusion of the skin using TO TCM 400 (Radiometer, Denmark) in the area of late RI manifested as RIF in patients with breast cancer.

However, the obtained results show the absence of significant difference between the values obtained during measurement of oxygen perfusion of the skin $\left(\mathrm{tcp} \mathrm{O}_{2}\right)$ in the area of RIF $(42.650 \pm 9.178 \mathrm{mmHg})$ and healthy tissue $(45.180 \pm 8.025 \mathrm{mmHg})$. Based on the obtained data, microcirculation in the irradiated area is not affected. In all likelihood, the main cause of RIF in the irradiated area is deficit and depletion of vegetative and differentiating intermitotic cells (fibroblasts) rather than RI of capillary endothelium.

According to the conclusions of some researches, frequency and severity of RIF significantly depend on cumulative absorbed dose and time after radiation therapy. The more time passes since irradiation, the higher is probability of severe fibrosis $[1,17]$. Presumably, deficit of vegetative and intermitotic fibroblasts and disorganization of collagen fibers cause tissue hypoxia in the irradiated area, and altered microcirculation is a subsequent event in the complex mechanism of pathogenesis of RIF. The obtained data shed a light on the development of late $\mathrm{RI}$ and show the necessity of further investigation of the problem.

\section{REFERENCES}

1. Topuzov E, Agishev T, Bozhok A, et al. Clinical and morphological characteristics of skin and subcutaneous fat damage after surgical treatment and radiation therapy in patients with breast cancer (literature review). Women Reproductive System Tumors 2017; 13: 25-33 (in Russian).

2. Van de Steen J, Soete G, Storme G. Adjuvant radiotherapy for breast cancer significantly improves overall survival: the missing link. Radiother Oncol 2000; 55: 263-72. 
3. Herskind C, Bamberg M, Rodemann H. The role of cytokines in the development of normal-tissue reactions after radiotherapy. Strahlenther Onkol 1998; 174: 12-5.

4. Sullivan B, Wilfred L. Late radiation-related fibrosis: pathogenesis, manifestations, and current management. Seminars Radiat Oncol 2003; 13: 274-89.

5. Trufanov G, Asaturyan M, Zharinov G. Radiation therapy: Textbook. V. 2. Moscow: GEOTAR-Media, 2007: 155-67 (in Russian).

6. Vishnevskiy A, Rudakov S, Milanov N. Course of wound process in local radiation injury. Available at: http:// medbe.ru/ materials/khirurgiya-grudnoy-kletki/techenieranevogo-protsessa-pri-mestnykh-luchevykh-povrezhdeniyakh/ (in Russian).

7. Reinke J, Sorg H. Wound Repair and Regeneration. Eur Surg Res 2012; 49: 35-43.

8. Tsyb A. Local radiation injury. Moscow: Meditsina, 1985. 240 p. (in Russian).

9. Epstein J, Emerton S, Gugliett A, et al. Assessment of epidermal growth factor in oral secretions of patients receiving radiation therapy for cancer. Oral Oncol 1997; 33: 359-63.

10. Kurpeshev O. Radiobiological analysis of early and late radiation injury development. Medical Radiol 1984; 29: 54-64 (in Russian).

11. Medrado A, Santos E, Reis S, et al. Influence of laser photobiomodulation upon connective tissue remodeling during wound healing. J Photochem Photobiol B 2008; 92: 144-52.

12. Johnson L, Jorgensen L, Adawi D, et al. The effect of preoperative radiotherapy on systemic collagen deposition and postoperative infective complications in rectal cancer patients. Dis Colon Rectum 2005; 48: 1573-80.

13. Vasiliev V, Vasiliev S, Karpov I, et al. The role of fat grafting in treatment of radiation-induced damage of soft tissue. Bull South Ural State University. Education, Healthcare, Sport series. March 2013. 214 p. (in Russian).

14. Sheffield $P$. Measuring tissue oxigen tension: a review. Undesea Hyper Med 1998; 25: 179-88.

15. Krupatkin A. Noninvasive estimation of human tissue respiration with wavelet - analysis of oxygen saturation and blood flow oscillations in skin microvessels. Human Physiology 2012; 38: 67 (in Russian).

16. Restrepo R, Hirst K, Wittnebel L, Wettstein R. AARC clinical practice guideline: transcutaneous monitoring of carbon dioxide and oxygen: 2012. Respir Care 2012; 57: 1955-62.

17. Veronesi U, Orecchia R, Luini A, et al. Full-dose intraoperative radiotherapy with electrons during breast-conserving surgery. Ann Surg 2005; 242: 101-6.

18. Richter K, Fink L, Hughes B, et al. Is the loss of endothelial thrombomodulin involved in the mechanism of chronicity in lateradiation enteropathy? Radiother Oncol 1997; 44: 65-71.

19. Hauer-Jensen M, Fink LM, Wang J. Radiation injury and the protein C pathway. Crit Care Med 2004; 32 (5 Suppl): S325-30.

20. Reinhold HS. The influence of radiation on blood vessels and circulation. Chapter IV. Structural changes inblood vessels. Curr Top Radiat Res Q 1974; 10: 58-74. 